\title{
QUALIDADE FÍSICA DE UM SOLO DEGRADADO EM RECUPERAÇÃO HÁ 6 ANOS
}

\section{PHYSICAL QUALITY OF A DEGRADED SOIL RECOVERY 6 YEARS AGO}

\section{Marlene Cristina Alves ${ }^{1}$, Edgar Bortoli dos Santos ${ }^{2}$, Ricardo Antônio Ferreira Rodrigues ${ }^{3}$, Otton Garcia de Arruda ${ }^{4}$}

\author{
${ }^{1}$ Engenheira Agrônoma, Profa. Dra. Curso Agronomia, UNESP - Ilha Solteira, SP, e- \\ mail: mcalves@agr.feis.unesp.br \\ ${ }^{2}$ Engenheiro Agrônomo, Msc. Agronomia, Pós Graduação em Agronomia, UNESP - \\ Ilha Solteira, SP \\ ${ }^{3}$ Engenheiro Agrícola, Prof. Dr. do Curso Agronomia, UNESP - Ilha Solteira, SP. \\ ${ }^{4}$ Engenheiro Agrônomo, Mestrando em Agronomia, Pós Graduação em Agronomia, \\ UNESP - Ilha Solteira, SP
}

\begin{abstract}
RESUMO
O biossólido é um composto passível de utilização agronômica, sendo fonte de nutrientes para as culturas e condicionador de solo. Neste sentido, desenvolveu-se um trabalho que teve por escopo estudar a influência da reaplicação de doses de biossólido na recuperação de atributos físicos do solo num Latossolo Vermelho degradado. O estudo foi realizado cinco meses após a reaplicação do biossólido, numa área em recuperação cultivada há seis anos com eucalipto e braquiária. $\mathrm{O}$ delineamento experimental foi em blocos casualizados com seis tratamentos e quatro repetições, sendo: Solo cultivado com eucalipto e braquiária sem adição de insumos; Solo cultivado com eucalipto e braquiária com adubação mineral; Solo cultivado com eucalipto e braquiária com reaplicação de 4,64 $\mathrm{mg} \mathrm{ha}^{-1}$ (base seca) de biossólido; Solo cultivado com eucalipto e braquiária com reaplicação de 9,28 $\mathrm{mg} \mathrm{ha}^{-1}$ (base seca) de biossólido; Solo exposto (sem qualquer cultivo ou adubação); Solo sob Vegetação natural de Cerrado. Estudou-se nas camadas do solo de 0,00-0,05; 0,05-0,10; 0,10-0,20 e de 0,20-0,40 m, os atributos físicos: macroporosidade; microporosidade; porosidade total e a densidade do solo. Verificou-se que a reaplicação do biossólido está recuperando o solo em relação aos atributos físicos, sobretudo nas camadas superficiais.

Palavras-chave: Degradação do solo. Lodo de esgoto. Propriedades físicas do solo. Condicionador de solo.
\end{abstract}

\footnotetext{
ABSTRACT

The sludge is a compound capable of agricultural use, a source of nutrients for crops and soil conditioner. In this sense, has developed a work which objective on studying the influence of reapplication of biosolids in the recovery of physical properties of soil in a degraded Oxisol. The work was conducted five months after the biosolids re-application in a recovery area cultivated for six years under eucalyptus and pasture. The experimental design was randomized blocks with six treatments and four replications, with: Soil under eucalyptus and pasture with
} 
no added inputs, soil under eucalyptus and pasture with mineral fertilization, soil under eucalyptus and pasture with re-application of $4.64 \mathrm{mg} \mathrm{ha}^{-1}$ (on dry basis) of sludge, soil under eucalyptus and pasture with re-application of $9.28 \mathrm{mg} \mathrm{ha}^{-1}$ (on dry basis) of sludge, soil exposed (without any cultivation or fertilization), soil with Savannah vegetation. Was studied in soil layers of $0.00-0.05,0.05-0.10,0.10-0.20$ and $0.20-0.40 \mathrm{~m}$, the physical attributes: macroporosity, microporosity; porosity and soil bulk density. It was found that reapplication of the sludge is regaining ground in relation to physical properties, especially in the surface layers.

Keywords: Soil degradation. Sewage sludge. Soil physics properties. Soil conditioner.

\section{INTRODUÇÃO}

Em todo aglomerado populacional, por menor que seja, ocorre à produção de esgoto sanitário que tem, inadequadamente, a disposição direta no meio ambiente ou existem ligações prediais para a coleta, transporte e tratamento do esgoto, ocorrendo à produção de efluentes e lodo de esgoto. Geralmente a disposição final desses resíduos é feita em aterros sanitários; incinerado ou uso agrícola.

O efluente é constituído pela parte sobrenadante com consistência líquida facilmente observada nas lagoas de estabilização das Estações de Tratamento de Esgoto (ETE) que findo o período programado para diminuição de sua carga patogênica e poluente pode ser lançada em cursos da água não oferecendo riscos de contaminação aos mananciais.

O lodo é constituído pela parte residual sedimentada em lagoas de tratamento de esgoto e que tem em sua composição alta carga patogênica e poluente oferecendo riscos à saúde humana e de contaminação do ambiente, entretanto quando submetido ao processo de decomposição microbiológica e destinado a uso benéfico é denominado biossólido (MATTHEWS, 2001; VAZ, GONÇALVES, 2002).

A disposição do biossólido vem gerando enorme preocupação dos legisladores, uma vez que, representa $60 \%$ dos custos de operação de uma estação de tratamento no caso da opção pela disposição em aterros sanitários. Em países desenvolvidos, a reciclagem agrícola do biossólido tem sido a principal forma de disposição final; esta destinação aumenta sua importância à medida que as outras formas costumam sofrer pressões ambientais, restringindo sua utilização, como nos casos da disposição marítima, opção proibida já em grande parte da Europa e Estados Unidos, além da disposição em aterros sanitários, devido à necessidade de extensas áreas e altos investimentos. A incineração, como forma de eliminação dos resíduos, apresenta custo muito elevado, sendo utilizada apenas para resíduos com alto poder impactante sobre o ambiente.

O uso do biossólido como fertilizante e condicionador do solo na recuperação de áreas degradadas é considerado hoje como a alternativa mais promissora de disposição final desse resíduo, pois além do baixo custo deste adubo orgânico, apresenta em sua composição macro, micronutrientes e matéria orgânica, resultando na melhoria da fertilidade do solo. A aplicação do biossólido pode resultar no aumento de matéria orgânica no solo. Com incremento do teor de matéria orgânica, a agregação do solo aumenta e, como conseqüência, seus atributos físicos podem ser alterados.

Pelas características do biossólido e partindo-se do conhecimento de alguns de seus efeitos como potencial fertilizante e condicionador de solos (GUEDES et al., 2006), acredita-se que o seu aproveitamento se constitua numa oportunidade de reciclagem dos nutrientes e, ao mesmo tempo, em solução do problema de sua acumulação em alta escala nas estações de tratamento (BOEIRA et al., 2007). No entanto, restrições vinculadas à qualidade do resíduo limitam o uso irrestrito em cultivo de produtos alimentícios, fato de menor relevância em ecossistemas florestais (FREIER et al., 2006). 
A adubação química e/ou orgânica é eficiente em plantações florestais com espécies particularmente do gênero Eucalyptus, e o uso do biossólido representa alternativa promissora, em plantações florestais (LIMA, 2005). O contato humano com biossólido é menor em reflorestamentos e o ciclo longo das árvores permite maior intervalo entre aplicações do que as culturas anuais, aumentando a eficiência de absorção do sistema radicular perene, profundo e bem distribuído das árvores (GUEDES, POGGIANI, 2003).

A aplicação do biossólido de esgoto em reflorestamento, sobretudo na cultura do eucalipto, vem sendo considerado uma alternativa viável, levando-se em consideração o isolamento destes plantios em relação aos núcleos urbanos, bem como a consumo destes produtos não estarem relacionados à alimentação humana.

Neste sentido, desenvolveu-se o presente trabalho que teve como objetivo estudar a influência da aplicação de doses de biossólido na recuperação e qualidade dos atributos físicos num Latossolo Vermelho degradado.

\section{MATERIAL E MÉTODOS}

\section{Área de estudo}

O estudo foi realizado numa área em processo de recuperação de 700 ha, atualmente pertencente à UNESP-Ilha Solteira e cultivada há cinco anos com eucalipto (Corymbia citriodora Hill Johnson) e braquiária (Urochloa decumbens Staff), nas coordenadas geográficas $51^{\circ} 22^{\prime}$ 39.61 " O e $20^{\circ} 22^{\prime} 36.79$ ' S, e altitude de $338 \mathrm{~m}$. Nessa área foi retirado solo até a profundidade de 8,60 m, para utilização na fundação e construção da Usina Hidrelétrica de Ilha Solteira-SP. Esta imensa área, sob Vegetação de cerrado, foi degradada há 40 anos, formando um ecossistema primário, com baixa capacidade de resiliência.

O solo original de acordo com a nomenclatura do Sistema Brasileiro de Classificação do Solo (EMBRAPA, 2006), é um Latossolo Vermelho Distrófico, textura franco argilo arenosa, (274 g $\mathrm{kg}^{-1}$ de argila, $526 \mathrm{~g} \mathrm{~kg}^{-1}$ de areia e $200 \mathrm{~g} \mathrm{~kg}^{-1} \mathrm{de}$ silte), profundo e muito intemperizado, de relevo suave a plano.

\section{Descrição dos tratamentos}

Em outubro de 2002 foi implantado um ensaio com aplicação de lodo de esgoto, adubo mineral e consórcio de eucalipto + pastagem braquiária. O consórcio de espécie arbórea com pastagem favorece a diversificação do sistema radicular, fornece contínuo aporte de matéria orgânica e condiciona favoravelmente o solo.

O delineamento experimental utilizado, em 2002, foi inteiramente casualizado, com seis tratamentos e quatro repetições, sendo: T1-(Consórcio Sem Insumos). Solo degradado, sem adição de insumos e cultivado com consórcio de eucalipto + pastagem braquiária; T2-(Adubação mineral). Solo degradado, com adubação mineral e cultivado com consórcio de eucalipto + pastagem braquiária; T3-(30 $\mathrm{mg} \mathrm{ha}^{-1}$ de lodo). Solo degradado, com aplicação de $30 \mathrm{mg} \mathrm{ha}^{-1}$ (base seca) de lodo de esgoto e cultivado com consórcio de eucalipto + pastagem braquiária; T4- $\left(60 \mathrm{mg} \mathrm{ha}^{-1} \mathrm{de}\right.$ lodo). Solo degradado, com aplicação de $60 \mathrm{mg} \mathrm{ha}^{-1}$ (base seca) de lodo de esgoto e cultivado com consórcio de eucalipto + pastagem braquiária; T5- (Solo Exposto). Solo degradado, sem adição de insumos e não cultivado e T6-Solo sob Vegetação natural de Cerrado.

O consórcio da cultura do eucalipto e pastagem braquiária foi implantado com espaçamento 2,0 $\mathrm{m} \times 1,5 \mathrm{~m}$, para a espécie arbórea, e nas entrelinhas a pastagem braquiária, semeada a lanço. Cada parcela ocupou uma área de $120 \mathrm{~m}^{2}(12 \mathrm{~m} \mathrm{x} 10 \mathrm{~m})$, com 40 plantas por parcela perfazendo 640 árvores no experimento. 
Depois de seis anos (dezembro de 2008), dando continuidade ao estudo de recuperação do solo degradado, foram realizadas coletas para análises de solo visando fornecer subsídios para recomendação das doses de biossólido e adubo mineral. Foi considerada a necessidade nutricional da cultura do eucalipto para aplicação da dose do biossólido, sendo de $30 \mathrm{~kg} \mathrm{ha}^{-1}$ de $\mathrm{N}, 60 \mathrm{~kg} \mathrm{ha}^{-1} \mathrm{de}$ $\mathrm{P}_{2} \mathrm{O}_{5}$ e $60 \mathrm{~kg}^{-1}$ de $\mathrm{K}_{2} \mathrm{O}$ e, para a aplicação da recomendação da adubação mineral, em conformidade com a análise química do solo, de $30 \mathrm{~kg} \mathrm{ha}^{-1}$ de $\mathrm{N}, 90 \mathrm{~kg} \mathrm{ha}^{-1}$ de $\mathrm{P}_{2} \mathrm{O}_{5}$ e $60 \mathrm{~kg} \mathrm{ha}^{-1}$ de $\mathrm{K}_{2} \mathrm{O}$ (BELLOTE, SILVA, 2008).

Em 2008, o delineamento experimental foi inteiramente casualizado com seis tratamentos e quatro repetições. Cada tratamento foi implantado na mesma parcela do experimento anterior, com a substituição do lodo de esgoto por biossólido, sendo: $\mathrm{T}_{1}$-Consórcio Sem Insumos; $\mathrm{T}_{2}$-Adubação mineral; $\mathrm{T}_{3}-\left(4,64 \mathrm{mg} \mathrm{ha}^{-1}\right.$ de biossólido). Solo degradado, com aplicação de 4,64 $\mathrm{mg} \mathrm{ha}^{-1}$ de biossólido e cultivado com consórcio de eucalipto + pastagem braquiária; $\mathrm{T}_{4}-\left(9,28 \mathrm{mg} \mathrm{ha}^{-1}\right.$ de biossólido). Solo degradado, com aplicação de $9,28 \mathrm{mg} \mathrm{ha}^{-1}$ de biossólido e cultivado com consórcio de eucalipto + pastagem braquiária; $\mathrm{T}_{5}$-Solo Exposto e $\mathrm{T}_{6}-$ Solo sob Vegetação natural de Cerrado.

\section{Origem e caracterização do biossólido reaplicado}

O biossólido utilizado foi fornecido pela Estação de Tratamento de Esgoto - ETE da Empresa de Saneamento Ambiental do Estado de São Paulo (SABESP), do município de Presidente Epitácio, SP.

Nesta, utiliza-se o tratamento em lagoa com sedimentação, permanecendo no sistema por tempo suficiente para favorecer sua digestão anaeróbia em condições controladas. Findo este período, o lodo é conduzido aos reservatórios onde fíca expostos a radiação solar por aproximadamente 90 dias, formando assim o biossólido digerido, que de acordo com Nogueira (2003) é aquele que sofreu estabilização biológica.

O biossólido apresentou a seguinte caracterização química: pH (in natura ) 5,5; umidade $0,09 \mathrm{~m}^{3} \mathrm{~m}^{-3}$; carbono orgânico 280,5 $\mathrm{g} \mathrm{kg}^{-1} ; \mathrm{N}$ amoniacal $2899 \mathrm{mg} \mathrm{kg}^{-1}$; $\mathrm{N}$ nitrato-nitrito $381 \mathrm{mg}$ $\mathrm{kg}^{-1}$; $\mathrm{N}$ total $38681 \mathrm{mg} \mathrm{kg}^{-1}$ e baixo teores de metais pesados

\section{Análise de agentes patogênicos}

A análise de agentes patogênicos do biossólido de esgoto doméstico foi realizada pela Universidade Federal do Paraná e pelos resultados obtidos foi classificado (Tabela 1) como tipo B, apresentando 0,02 de ovos de helmintos, 0,03 de protozoários e 1,8.102 de coliformes fecais por grama de sólidos totais, sendo, portanto considerado passível de utilização agrícola (CETESB, 1999). Salienta-se ainda, que aplicação no eucalipto (silvicultura) atendeu ao preceito préestabelecido na Resolução CONAMA n 375/2006 (BRASIL, 2006), que proíbe a utilização de qualquer classe de biossólido de esgoto ou produto derivado em pastagens e cultivo de olerícolas, tubérculos e raízes, e culturas inundadas, bem como as demais culturas cuja parte comestível entre em contato com o solo.

Tabela 1 - Concentração de agentes patogênicos no biossólido utilizado no experimento.

\begin{tabular}{cccc} 
Agente patogênico & Unidade $^{\mathbf{1}}$ & $\begin{array}{c}\mathbf{N}^{\circ} \text { de } \\
\text { organismos }\end{array}$ & CETESB (1999) $^{\mathbf{2}}$ \\
\hline Coliformes Fecais & NMP/g ST & $1,8.10^{2}$ & $2,0.10^{6}$ \\
Helmintos & $\mathrm{n}^{\circ}$ de ovos/g ST & 0,02 & 0,25 \\
Protozoários & $\mathrm{n}^{\circ}$ de ovos/g ST & 0.03 & 0,25
\end{tabular}

${ }^{(1)}$ Dados à base seca. NMP - Número mais provável; ST - Sólidos Totais. Valores considerados limites pela CETESB (1999). ${ }^{(2)}$ Analisado pelo CEPPA/Universidade Federal do Paraná. 


\section{Cálculo da dose de biossólido aplicada}

Os teores para N, P, K contidos no biossólido foram respectivamente de 0,03868, 0,0055 e $0,0006 \mathrm{~kg} \mathrm{~kg}^{-1}$, na forma elementar, foram ajustados para a forma $\mathrm{N}, \mathrm{P}_{2} \mathrm{O}_{5}$ e $\mathrm{K}_{2} \mathrm{O}$, com valores de 0,$03868 ; 0,012597$ e $0,000723 \mathrm{~kg} \mathrm{~kg}^{-1}$ de matéria seca (MS), respectivamente.

Foram determinadas as quantidades de nutrientes disponíveis às plantas no decorrer do ano, em que se considerou a mineralização de $30 \%$ do $\mathrm{N}$ orgânico e a volatilização de $30 \%$ do $\mathrm{N}$ amoniacal, segundo Andreoli et al. (2001). Quanto ao fósforo, foi considerada uma disponibilidade de 70\% (RAIJ et al., 1997).

Para o potássio foi considerado disposição integral para a cultura, mesmo porque os valores fornecidos ao solo pelo biossólido foram irrisórios, necessitando de significativa dose complementar para atender a necessidade da cultura.

$\mathrm{Na}$ Tabela 2 estão relacionados a quantidade fornecida de nutrientes pelas diferente doses do biossólido, a necessidade da cultura, valor necessário de complementação com adubação mineral em virtude do desbalanço nutricional do biossólido e os excedentes para a cultura eucalipto que poderão ser disponibilizados para a braquiária.

Tabela 2 - Teores de nutrientes disponibilizados pelo biossólido, no decorrer do ano, e necessidade complementada com adubo mineral e excedentes gerados pelo biossólido.

\begin{tabular}{lcccccc}
\hline & \multicolumn{5}{c}{ Macronutriente } \\
\cline { 2 - 7 } & Nitrogênio & Fósforo & \multicolumn{1}{c}{ Potássio } \\
\cline { 2 - 7 } & \multicolumn{5}{c}{ Doses de Biossólidos (mg ha $\left.{ }^{-1}\right)$} \\
\cline { 2 - 7 } & 4,64 & 9,28 & 4,64 & 9,28 & 4,64 & 9,28 \\
\hline Quantidade aplicada (kg ha-1) & 60,46 & 120,92 & 37,39 & 74,77 & 3,06 & 6,22 \\
Necessidade da Cultura (kg ha-1) & 30 & 30 & 60 & 60 & 60 & 60 \\
Complementação com adubo mineral & 0 & 0 & 22,61 & 0 & 56,94 & 53,78 \\
\hline
\end{tabular}

O nitrogênio disponível $\left(\mathrm{N}_{\text {disponível }}\right)$ foi calculado com os dados em $\mathrm{kg}$ de $\mathrm{N} \mathrm{kg}$-1 de matéria seca, aplicados na equação abaixo:

$$
\mathrm{N}_{\text {disponível }}=\left(\mathrm{N}_{\text {orgânico }} \times 0,3\right)+\left(\mathrm{N}_{\text {amoniacal }} \times 0,7\right)+\mathrm{N}_{\text {nitrato-nitrico }}
$$

Em que Ndisponível é a quantidade de Nitrogênio fornecido com a aplicação do biossólido (kg de $\mathrm{N} \mathrm{kg}^{-1}$ de MS); Norgânico, Namoniacal e Nnitrato-nitrico são os valores obtidos na caracterização do biossólido.

Desta forma, o nitrogênio disponível foi assim determinado:

$$
\text { Ndisponível }=0,03540 \times 0,3+0,002899 \times 0,7+0,00038=0,013029 \mathrm{~kg} \mathrm{de} \mathrm{N} \mathrm{kg}{ }^{-1} \text { de MS }
$$

Para as doses de 4,64 e 9,28 $\mathrm{mg} \mathrm{ha}^{-1}$ de biossólido de esgoto (base seca), foram aplicados, respectivamente, $60,46 \mathrm{e} 120,92 \mathrm{~kg} \mathrm{ha}^{-1}$ de nitrogênio prontamente disponível às plantas e que atendem as necessidades da cultura (Tabela 2).

Portanto, de acordo com as considerações da necessidade da cultura do eucalipto, os tratamentos com a aplicação do biossólido foram assim distribuídos: Solo cultivado com eucalipto e 
braquiária com aplicação da dose de 4,64 $\mathrm{mg} \mathrm{ha}^{-1}$ de biossólido; Solo cultivado com eucalipto e braquiária com aplicação da dose de $9,28 \mathrm{mg} \mathrm{ha}^{-1}$ de biossólido.

\section{Forma de aplicação do biossólido e do adubo mineral}

O biossólido de esgoto foi aplicado manualmente com auxílio de recipientes com capacidade de $5 \mathrm{~L}$, superficialmente e sem incorporação, empregando-se duas vezes a medida para o dobro da dose em uma área de $3,0 \mathrm{~m}^{2}$. O adubo químico e o calcário foram distribuídos a lanço, em cobertura.

\section{Análise da qualidade física do solo}

Para a análise da qualidade física do solo, foram retiradas amostras indeformadas com anéis volumétricos, utilizados para a determinação da densidade do solo, porosidade total e microporosidade (EMBRAPA, 1997). A densidade do solo foi determinada pelo método do anel volumétrico e a porosidade total obtida pela diferença entre a massa do solo saturado e a massa do solo seco em estufa a $110^{\circ} \mathrm{C}$, durante $24 \mathrm{~h}$. A microporosidade foi determinada pelo método da mesa de tensão, com uma coluna de água de $0,60 \mathrm{~m}$ de altura. Pela diferença entre a porosidade total e a microporosidade, obteve-se a macroporosidade. Estas amostras foram retiradas em dezembro de 2008, cinco anos após a instalação do experimento, e depois da reaplicação do biossólido, em maio de 2009, em quatro camadas de solo: 0,00-0,05; 0,05-0,10; 0,10-0,20 e de 0,20$0,40 \mathrm{~m}$ e, em três pontos por parcela.

\section{RESULTADOS E DISCUSSÃO}

Com base nos resultados obtidos (Tabelas 3 e 4) observou-se diferenças significativas ao nível de $5 \%$ entre os tratamentos, para os atributos físicos do solo estudados e, em todas as camadas de solo, exceção para a microporosidade na camada de 0,10-0,20 m (Tabela 3), antes da aplicação do biossólido e para a porosidade total na camada de 0,10-0,20 m (Tabela 4), após a aplicação do biossólido.

De forma geral, tanto antes da aplicação do biossólido (Tabela 3) como após a aplicação (Tabela 4), verificou-se que o solo está recuperando a qualidade física. Essa melhoria é evidenciada pelas diferenças dos valores observados entre os tratamentos de recuperação e o solo degradado sem adição de insumos e cultivado com consórcio eucalipto + pastagem braquiária (Tabela 4). Ressaltam-se também as maiores semelhanças entre as propriedades físicas do solo no qual se aplicou a maior dose de biossólido de esgoto e as do solo sob Vegetação de Cerrado (Tabela 4).

$\mathrm{O}$ valor da densidade do solo foi influenciado pelos tratamentos tanto na dose de $4,64 \mathrm{mg}$ ha ${ }^{-1}$ de biossólido $\left(1,40 \mathrm{~kg} \mathrm{dm}^{-3}\right)$ como na de $9,28 \mathrm{mg} \mathrm{ha}^{-1}$ de biossólido $\left(1,36 \mathrm{~kg} \mathrm{dm}^{-3}\right)$, na camada de 0-0,05 m, não diferindo estatisticamente ao nível de $5 \%$ do tratamento com Vegetação de Cerrado $\left(1,27 \mathrm{~kg} \mathrm{dm}^{-3}\right)$. 
Tabela 3 - Valores médios dos atributos físicos, teste $\mathrm{F}$, coeficiente de variação $(\mathrm{CV})$ e diferença mínima significativa (DMS), obtidos nas diferentes camadas de solo em relação aos tratamentos estudados, antes da reaplicação do biossólido (Tratamentos instalados há 6 anos).

\begin{tabular}{|c|c|c|c|c|c|}
\hline \multirow{2}{*}{$\begin{array}{l}\text { Atributos } \\
\text { Físicos }\end{array}$} & \multirow[t]{2}{*}{ Tratamentos } & \multicolumn{4}{|c|}{ Camada de solo (m) } \\
\hline & & $0-0,05$ & $\mathbf{0 , 0 5 - 0 , 1}$ & $0,1-0,2$ & $0,2-0,4$ \\
\hline \multirow{9}{*}{$\begin{array}{c}\text { Densidade } \\
\text { do } \\
\text { solo } \\
\left(\mathrm{kg} \mathrm{dm}^{-3}\right)\end{array}$} & Consórcio Sem Insumos & $1,55 b$ & $1,55 b$ & $1,62 \mathrm{ab}$ & $1,82 \mathrm{a}$ \\
\hline & Adubação mineral & $1,55 b$ & $1,51 b$ & $1,47 b$ & $1,73 a$ \\
\hline & $30 \mathrm{mg} \mathrm{ha}^{-1}$ de lodo & $1,39 b$ & $1,54 b$ & $1,59 \mathrm{ab}$ & $1,69 \mathrm{ab}$ \\
\hline & $60 \mathrm{mg} \mathrm{ha}^{-1}$ de lodo & $1,42 b c$ & $1,52 b$ & $1,68 \mathrm{ab}$ & $1,67 \mathrm{ab}$ \\
\hline & Solo Exposto & $1,77 \mathrm{a}$ & $1,82 \mathrm{a}$ & $1,80 \mathrm{a}$ & $1,84 \mathrm{a}$ \\
\hline & Vegetação de Cerrado & $1,13 \mathrm{~d}$ & $1,40 \mathrm{~b}$ & $1,52 \mathrm{ab}$ & $1,40 \mathrm{~b}$ \\
\hline & $F-5 \%$ & $39,475^{*}$ & $13,741 *$ & $3,640^{*}$ & $4,991 *$ \\
\hline & $\mathrm{CV}-\%$ & 4,43 & 4,85 & 7,7 & 8,46 \\
\hline & DMS - 5\% & 0,153 & 0,173 & 0,286 & 0,329 \\
\hline \multirow{9}{*}{$\begin{array}{c}\text { Macro- } \\
\text { porosidade } \\
\left(\mathrm{m}^{3} \mathrm{~m}^{-3}\right)\end{array}$} & Consórcio Sem Insumos & $0,06 \mathrm{~b}$ & $0,06 \mathrm{~b}$ & $0,06 b$ & $0,06 b$ \\
\hline & Adubação mineral & $0,08 b$ & $0,09 a b$ & $0,11 \mathrm{ab}$ & $0,06 b$ \\
\hline & $30 \mathrm{mg} \mathrm{ha}^{-1}$ de lodo & $0,13 a b$ & $0,07 \mathrm{~b}$ & $0,07 \mathrm{~b}$ & $0,07 \mathrm{~b}$ \\
\hline & $60 \mathrm{mg} \mathrm{ha}^{-1}$ de lodo & $0,13 a b$ & $0,11 \mathrm{ab}$ & $0,06 b$ & $0,06 b$ \\
\hline & Solo Exposto & $0,06 b$ & $0.06 \mathrm{~b}$ & $0,06 b$ & $0,05 b$ \\
\hline & Vegetação de Cerrado & $0,22 \mathrm{a}$ & $0,15 \mathrm{a}$ & $0,13 a$ & $0,16 \mathrm{a}$ \\
\hline & $F-5 \%$ & $6,182 *$ & $5,745^{*}$ & $7,757 *$ & $19,066^{*}$ \\
\hline & $\mathrm{CV}-\%$ & 42,24 & 32,93 & 26,45 & 24,66 \\
\hline & DMS - 5\% & 0,104 & 0,068 & 0.050 & 0,044 \\
\hline \multirow{9}{*}{$\begin{array}{c}\text { Micro- } \\
\text { porosidade } \\
\left(\mathrm{m}^{3} \mathrm{~m}^{-3}\right)\end{array}$} & Consórcio Sem Insumos & $0,32 \mathrm{a}$ & $0,31 \mathrm{a}$ & 0,30 & $0,29 \mathrm{ab}$ \\
\hline & Adubação mineral & $0,32 \mathrm{a}$ & $0,32 \mathrm{a}$ & 0,30 & $0,29 \mathrm{ab}$ \\
\hline & $30 \mathrm{mg} \mathrm{ha}^{-1}$ de lodo & $0,29 \mathrm{ab}$ & $0,30 \mathrm{a}$ & 0,28 & $0,29 \mathrm{a}$ \\
\hline & $60 \mathrm{mg} \mathrm{ha}^{-1}$ de lodo & $0,32 \mathrm{a}$ & $0,29 \mathrm{ab}$ & 0,28 & $0,28 \mathrm{ab}$ \\
\hline & Solo Exposto & $0,25 b$ & $0,25 b$ & 0,24 & $0,24 \mathrm{ab}$ \\
\hline & Vegetação de Cerrado & $0,26 b$ & $0,28 \mathrm{ab}$ & 0,24 & $0,24 b$ \\
\hline & $F-5 \%$ & $9,130^{*}$ & $7,370^{*}$ & $4,181 \mathrm{~ns}$ & $4,205^{*}$ \\
\hline & $\mathrm{CV}-\%$ & 7,01 & 6,19 & 8,89 & 8,82 \\
\hline & DMS - $5 \%$ & 0,047 & 0,041 & 0,056 & 0,055 \\
\hline \multirow{9}{*}{$\begin{array}{c}\text { Porosidade } \\
\text { Total } \\
\left(\mathrm{m}^{3} \mathrm{~m}^{-3}\right)\end{array}$} & Consórcio Sem Insumos & $0,38 \mathrm{bc}$ & $0,37 \mathrm{ab}$ & $0,36 a b$ & $0,34 a b$ \\
\hline & Adubação mineral & $0,40 \mathrm{abc}$ & $0,41 \mathrm{a}$ & $0,41 \mathrm{a}$ & $0,35 \mathrm{ab}$ \\
\hline & $30 \mathrm{mg} \mathrm{ha}^{-1}$ de lodo & $0,42 \mathrm{ab}$ & $0,37 \mathrm{ab}$ & $0,35 \mathrm{ab}$ & $0,36 \mathrm{a}$ \\
\hline & $60 \mathrm{mg} \mathrm{ha}^{-1}$ de lodo & $0,45 \mathrm{ab}$ & $0,40 \mathrm{a}$ & $0,35 \mathrm{ab}$ & $0,34 \mathrm{ab}$ \\
\hline & Solo Exposto & $0,32 \mathrm{c}$ & $0,30 \mathrm{~b}$ & $0,28 \mathrm{~b}$ & $0,28 \mathrm{~b}$ \\
\hline & Vegetação de Cerrado & $0,42 \mathrm{a}$ & $0,43 a$ & $0,37 \mathrm{a}$ & $0,32 \mathrm{a}$ \\
\hline & F $-5 \%$ & $9,094 *$ & $7,976^{*}$ & $4,326^{*}$ & $4,852 *$ \\
\hline & $\mathrm{CV}-\%$ & 9,42 & 8,45 & 11,28 & 9,99 \\
\hline & DMS - 5\% & 0,087 & 0,073 & 0,092 & 0.079 \\
\hline
\end{tabular}


Tabela 4 - Valores médios da densidade; macroporosidade; microporosidade e porosidade total, observados nos tratamentos e nas diferentes camadas do solo, após a aplicação do biossólido ${ }^{(1)}$.

\begin{tabular}{|c|c|c|c|c|c|}
\hline \multirow{2}{*}{$\begin{array}{l}\text { Atributos } \\
\text { Físicos }\end{array}$} & \multirow[t]{2}{*}{ Tratamentos } & \multicolumn{4}{|c|}{ Camada de solo $(\mathrm{m})$} \\
\hline & & 0-0,05* & $\mathbf{0 , 0 5 - 0 , 1}$ & $0,1-0,2$ & $0,2-0,4$ \\
\hline \multirow{9}{*}{$\begin{array}{c}\text { Densidade } \\
\text { do } \\
\text { solo } \\
\left.(\mathrm{kg} \mathrm{dm})^{-3}\right)\end{array}$} & Consórcio Sem Insumos & $1,54 \mathrm{~b}$ & $1,57 \mathrm{~b}$ & $1,56 \mathrm{~b}$ & $1,86 \mathrm{a}$ \\
\hline & Adubação mineral & $1,48 \mathrm{bc}$ & $1,58 \mathrm{~b}$ & $1,61 \mathrm{ab}$ & $1,82 \mathrm{a}$ \\
\hline & 4,64 $\mathrm{mg} \mathrm{ha}^{-1}$ de biossólido & $1,40 \mathrm{bcd}$ & $1,54 \mathrm{bc}$ & $1,64 \mathrm{ab}$ & $1,84 \mathrm{a}$ \\
\hline & $9,28 \mathrm{mg} \mathrm{ha}^{-1}$ de biossólido & $1,36 \mathrm{~cd}$ & $1,48 \mathrm{bc}$ & $1,61 \mathrm{ab}$ & $1,69 \mathrm{ab}$ \\
\hline & Solo exposto & $1,73 \mathrm{a}$ & $1,72 \mathrm{a}$ & $1,72 \mathrm{a}$ & $1,81 \mathrm{a}$ \\
\hline & Vegetação de Cerrado & $1,27 \mathrm{~d}$ & $1,45 \mathrm{c}$ & $1,53 \mathrm{~b}$ & $1,40 \mathrm{~b}$ \\
\hline & $F-5 \%$ & $25,80 *$ & $17,08^{*}$ & $5,88^{*}$ & $6,36^{*}$ \\
\hline & CV- \% & 4,33 & 2,96 & 3,51 & 8,04 \\
\hline & DMS - 5\% & 0,145 & 0,105 & 0,13 & 0,321 \\
\hline \multirow{9}{*}{$\begin{array}{l}\text { Macro- } \\
\text { porosidade } \\
\left(\mathrm{m}^{3} \mathrm{~m}^{-3}\right)\end{array}$} & Consórcio Sem Insumos & $0,10 \mathrm{~cd}$ & $0,10 \mathrm{bc}$ & $0,12 \mathrm{~b}$ & $0,06 \mathrm{~b}$ \\
\hline & Adubação mineral & $0,13 \mathrm{bc}$ & $0,12 \mathrm{ab}$ & $0,10 \mathrm{bc}$ & $0,06 \mathrm{~b}$ \\
\hline & 4,64 $\mathrm{mg} \mathrm{ha}^{-1}$ de biossólido & $0,18 \mathrm{ab}$ & $0,12 \mathrm{ab}$ & $0,09 \mathrm{c}$ & $0,06 \mathrm{~b}$ \\
\hline & $9,28 \mathrm{mg} \mathrm{ha}^{-1}$ de biossólido & $0,21 \mathrm{a}$ & $0,15 \mathrm{a}$ & $0,10 \mathrm{bc}$ & $0,09 \mathrm{~b}$ \\
\hline & Solo exposto & $0,06 \mathrm{~d}$ & $0,06 \mathrm{c}$ & $0,06 \mathrm{~d}$ & $0,04 \mathrm{~b}$ \\
\hline & Vegetação de Cerrado & $0,18 \mathrm{ab}$ & $0,14 \mathrm{a}$ & $0,16 \mathrm{a}$ & $0,16 \mathrm{a}$ \\
\hline & $F-5 \%$ & $17,63 *$ & $14,26^{*}$ & $54,88^{*}$ & $15,21 *$ \\
\hline & $\mathrm{CV}-\%$ & 18,97 & 16,22 & 9,2 & 28,4 \\
\hline & DMS - 5\% & 0,063 & 0,043 & 0,022 & 0,052 \\
\hline \multirow{9}{*}{$\begin{array}{l}\text { Micro- } \\
\text { porosidade } \\
\left(\mathrm{m}^{3} \mathrm{~m}^{-3}\right)\end{array}$} & Consórcio Sem Insumos & 0,28 & 0,27 & $0,25 \mathrm{~b}$ & 0,26 \\
\hline & Adubação mineral & 0,28 & 0,26 & $0,26 \mathrm{~b}$ & 0,25 \\
\hline & 4,64 mg ha ${ }^{-1}$ de biossólido & 0,25 & 0,25 & $0,24 \mathrm{bc}$ & 0,25 \\
\hline & $9,28 \mathrm{mg} \mathrm{ha}^{-1}$ de biossólido & 0,24 & 0,25 & $0,26 \mathrm{ab}$ & 0,25 \\
\hline & Solo exposto & 0,31 & 0,29 & $0,29 \mathrm{a}$ & 0,28 \\
\hline & Vegetação de Cerrado & 0,27 & 0,24 & $0,21 \mathrm{c}$ & 0,24 \\
\hline & $F-5 \%$ & $2,64 \mathrm{~ns}$ & $2,46 \mathrm{~ns}$ & $13,95^{*}$ & $1,08 \mathrm{~ns}$ \\
\hline & $\mathrm{CV}-\%$ & 10,74 & 8,76 & 6,07 & 12,07 \\
\hline & DMS - $5 \%$ & 0,067 & 0,053 & 0,035 & 0,071 \\
\hline \multirow{9}{*}{$\begin{array}{c}\text { Porosidade } \\
\text { Total } \\
\left(\mathrm{m}^{3} \mathrm{~m}^{-3}\right)\end{array}$} & Consórcio Sem Insumos & $0,39 \mathrm{c}$ & $0,37 \mathrm{ab}$ & 0,37 & $0,32 \mathrm{~b}$ \\
\hline & Adubação mineral & $0,41 \mathrm{bc}$ & $0,38 \mathrm{ab}$ & 0,36 & $0,32 \mathrm{ab}$ \\
\hline & 4,64 mg ha ${ }^{-1}$ de biossólido & $0,44 \mathrm{ab}$ & $0,37 \mathrm{ab}$ & 0,33 & $0,30 \mathrm{~b}$ \\
\hline & $9,28 \mathrm{mg} \mathrm{ha}^{-1}$ de biossólido & $0,45 \mathrm{a}$ & $0,40 \mathrm{a}$ & 0,35 & $0,34 \mathrm{ab}$ \\
\hline & Solo exposto & $0,37 \mathrm{c}$ & $0,35 \mathrm{~b}$ & 0,35 & $0,33 \mathrm{ab}$ \\
\hline & Vegetação de Cerrado & $0,45 \mathrm{a}$ & $0,39 \mathrm{ab}$ & 0,37 & $0,40 \mathrm{a}$ \\
\hline & $F-5 \%$ & $13,84^{*}$ & $4,24 *$ & $2,87 \mathrm{~ns}$ & $3,65^{*}$ \\
\hline & $\mathrm{CV}-\%$ & 4,63 & 4,63 & 4,9 & 10,55 \\
\hline & DMS - 5\% & 0,044 & 0,04 & 0,04 & 0,081 \\
\hline
\end{tabular}

${ }^{(1)}$ Médias seguidas de letras iguais, na mesma coluna, não diferem entre si pelo teste de Tukey, a $5 \%$ de probabilidade.

Isso é um indicativo da recuperação deste atributo físico, uma vez que as médias para estes tratamentos se aproximaram da média da Vegetação de Cerrado.

Todos os valores médios da densidade do solo para a referida camada, exceção feita ao tratamento Solo Exposto $\left(1,73 \mathrm{~kg} \mathrm{dm}^{-3}\right)$, foram inferiores a $1,55 \mathrm{~kg} \mathrm{dm}^{-3}$ que foi o valor considerado como densidade crítica, para o bom desenvolvimento do sistema radicular em solos com textura média (REICHERT et al. 2003). 
Em experimento avaliando a densidade do solo e infiltração de água como indicadores da qualidade física de um Latossolo Vermelho distrófico em recuperação foi relatado melhorias na qualidade do solo com o seu preparo e adição de biossólido de esgoto e adubos verdes, e verificado que os indicadores utilizados (densidade e infiltração de água do solo) foram adequados (ALVES et al., 2007).

$\mathrm{Na}$ camada de 0,05-0,10 m, com relação à densidade do solo foi observado comportamento similar ao ocorrido na camada de 0-0,05 m não havendo diferença significativa, ao nível de 5\%, entre o tratamento Vegetação de Cerrado $\left(1,45 \mathrm{~kg} \mathrm{dm}^{-3}\right)$, e os tratamentos onde foi aplicado o biossólido (maior dose, 1,48 e menor, 1,54). No entanto, os tratamentos onde foi aplicado o biossólido não obtiveram melhor desempenho que os tratamentos com Adubação Mineral (1,58 kg $\left.\mathrm{dm}^{-3}\right)$ e Consórcio Sem Insumos $\left(1,57 \mathrm{~kg} \mathrm{dm}^{-3}\right)$.

Ainda, para a camada de 0,05-0,10 m observou-se para o Solo Exposto um valor alto para a densidade do solo $\left(1,72 \mathrm{~kg} \mathrm{dm}^{-3}\right)$, acima do considerado crítico $\left(1,55 \mathrm{~kg} \mathrm{dm}^{-3}\right)$, e diferença estatística com as médias dos demais tratamentos, demonstrando melhoria dos atributos físicos do solo para esta camada. Num experimento visando à recuperação de um solo degradado com adubos verdes e aplicação de biossólido a densidade do solo foi o atributo físico mais sensível para detectar alterações na recuperação do solo estudado (ALVES et al., 2007).

Em relação à camada de 0,10-0,20 m (Tabela 4) observou-se que os demais tratamentos apresentaram melhor desempenho quando comparados ao Solo Exposto $\left(1,72 \mathrm{~kg} \mathrm{dm}^{-3}\right)$ para o atributo densidade do solo com médias estatisticamente inferiores, evidenciando melhorias neste atributo e recuperação do solo degradado.

Campos, Alves (2008) em experimento com doses de biossólido de esgoto e adubação mineral verificaram que a densidade do solo e a porosidade total foram os melhores indicadores da recuperação do solo. Salienta-se ainda que para os demais tratamentos não diferiram estatisticamente entre si para este atributo na referida camada de solo estudada .

$\mathrm{Na}$ camada de 0,20-0,40 m não foi observado diferença estatística entre as médias dos tratamentos para a densidade do solo, exceção feita ao tratamento com Vegetação de Cerrado (1,40 $\mathrm{kg} \mathrm{dm}^{-3}$ ), sendo indicativo que o biossólido teve pouca influência na recuperação do solo degradado nesta camada, em virtude da aplicação sem incorporação. Ainda na referida camada, não foi observado diferença entre o tratamento de $9,28 \mathrm{mg} \mathrm{ha}^{-1}$ de biossólido $\left(1,69 \mathrm{~kg} \mathrm{dm}^{-3}\right)$ e o de Vegetação de Cerrado, havendo, portanto, influência do biossólido na recuperação deste atributo até a camada de $0,40 \mathrm{~m}$ de profundidade no solo.

Para o atributo macroporosidade na camada de 0-0,05 $\mathrm{m}$ foi observado que as médias dos tratamentos com doses de biossólidos (4,64 mg ha $\mathrm{mg}^{-1}, 0,18 \mathrm{~m}^{3} \mathrm{~m}^{-3}$ e 9,28 $\left.\mathrm{mg} \mathrm{ha}^{-1}, 0,21 \mathrm{~m}^{3} \mathrm{~m}^{-3}\right)$; Vegetação de Cerrado $\left(0,18 \mathrm{~m}^{3} \mathrm{~m}^{-3}\right)$, os quais não diferiram estatisticamente entre si, e o de Adubação Mineral $\left(0,13 \mathrm{~m}^{3} \mathrm{~m}^{-3}\right)$ foram superiores em relação ao Solo Exposto, indicando recuperação para este atributo.

Melo et al. (2004) num experimento com a aplicação de diferentes doses de biossólido obtiveram resultados positivos com a macroporosidade, sendo superior na camada de 0-0,10 m, a partir de 47,5 $\mathrm{mg} \mathrm{ha}^{-1}$ e 50,0 $\mathrm{mg} \mathrm{ha}^{-1}$ de biossólido, num Latossolo Vermelho distrófico e Latossolo Vermelho eutroférrico, respectivamente.

Na camada de 0,05-0,10 $\mathrm{m}$ (Tabela 4) o tratamento com a dose de 9,28 $\mathrm{mg} \mathrm{ha}^{-1}$ de biossólido $\left(0,15 \mathrm{~m}^{3} \mathrm{~m}^{-3}\right)$ teve comportamento similar ao do Vegetação de Cerrado $\left(0,14 \mathrm{~m}^{3} \mathrm{~m}^{-3}\right)$, porém esta dose não conseguiu superar estatisticamente aquela de $4,64 \mathrm{mg} \mathrm{ha}^{-1}$ de biossólido $\left(0,12 \mathrm{~m}^{3} \mathrm{~m}^{-3}\right)$ e a com Adubação Mineral $\left(0,12 \mathrm{~m}^{3} \mathrm{~m}^{-3}\right)$. Não foi observada diferença entre o tratamento Consórcio Sem Insumos $\left(0,10 \mathrm{~m}^{3} \mathrm{~m}^{-3}\right)$ e Solo Exposto $\left(0,06 \mathrm{~m}^{3} \mathrm{~m}^{-3}\right)$.

Para a camada de $0,10-0,20 \mathrm{~m}$, para este mesmo atributo, observou-se que não ocorreu diferença estatística entre as médias dos tratamentos onde foram aplicadas as diferentes doses de biossólido e a Adubação Mineral; sendo observada a diferença entre a menor dose e o Consórcio 
Sem Insumos, porém, todos os tratamentos diferiram estatisticamente do Solo Exposto e Vegetação de Cerrado. Houve melhoria do atributo físico estudado, porém os tratamentos estão agindo de forma semelhante para a referida camada de solo.

Em relação à camada de $0,20-0,40 \mathrm{~m}$, para a macroporosidade, não foi observado diferença significativa entre as médias dos tratamentos, exceção feita ao tratamento Vegetação de Cerrado que diferiu estatisticamente dos demais, indicando que os tratamentos não estão tendo influência na recuperação deste atributo na camada mais profunda analisada.

Convém salientar que para todos os tratamentos estudados os valores de macroporosidade nesta camada estavam abaixo de $0,10 \mathrm{~m}^{3} \mathrm{~m}^{-3}$, considerado crítico para um bom desenvolvimento do sistema radicular (GREENLAND, 1981).

Tratando-se do atributo microporosidade nas camadas de $0-0,05 \mathrm{~m}, 0,05-0,10 \mathrm{~m}$ e de 0,20 0,40 m não foram observadas diferenças significativa entre as médias dos tratamentos (Tabela 4). Isto é, os tratamentos não interferiram na recuperação do solo degradado para o referido atributo. Comportamento análogo ao descrito anteriormente foi observado por Melo et al. (2004), quando não se verificou a recuperação da microporosidade para as camadas de solo analisadas e as doses de biossólido aplicadas.

No presente estudo, exceção foi observada na camada $0,10-0,20 \mathrm{~m}$, na qual o tratamento com menor dose de biossólido não diferiu do tratamento com Vegetação de Cerrado, e este último diferiu estatisticamente da maior dose de biossólido. Observou-se aumento da microporosidade no solo degradado e em processo de recuperação comparando-se com a condição de Vegetação natural de Vegetação Natural de Cerrado, e que pode ser um indicativo de maior compactação nesta camada.

Pelas médias obtidas para o atributo porosidade total na camada de 0-0,05 $\mathrm{m}$ foi observado que o tratamento com vegetação natural de Vegetação de Cerrado não diferiu estatisticamente dos tratamentos onde ocorreu a aplicação das diferentes doses de biossólido, sendo um indicativo da recuperação do solo degradado (Tabela 4). Para o referido atributo os tratamentos Adubação mineral, Solo Exposto e Consórcio Sem Insumos não diferiram estatisticamente entre si, indicando que estes tratamentos estão com menores efeitos na recuperação do solo degradado. No entanto os dois últimos diferiram do tratamento com Vegetação de Cerrado e com diferentes doses de biossólido, reforçando os indícios elencados anteriormente. Navas et al. (1998) observaram um incremento da porosidade total do solo de $0,38 \mathrm{~m}^{3} \mathrm{~m}^{-3}$ para $0,49 \mathrm{~m}^{3} \mathrm{~m}^{-3}$, na camada de $0-0,20 \mathrm{~m}$, quando foram aplicados $320 \mathrm{mg} \mathrm{ha}^{-1}$ de biossólido de esgoto.

$\mathrm{Na}$ camada de 0,05-0,10 m, para a porosidade total, foi observado que houve diferença entre o Solo Exposto (alto grau de degradação) e o tratamento com a maior dose de biossólido (Tabela 4). Estes dois tratamentos não diferiram dos demais. Tal comportamento concorda com os resultados por Jorge et al. (1991) obtidos em um Latossolo Vermelho-Escuro argiloso, não sendo observados efeitos sobre a porosidade total determinada após quatro anos de aplicação de biossólido de esgoto em doses de até $80 \mathrm{mg} \mathrm{ha}^{-1}$, em forma parcelada ou em uma única vez. Esses resultados que corroboram aqueles de Melo et al., 2004 que após a aplicação de até 50,0 $\mathrm{mg} \mathrm{ha}^{-1}$ de biossólido, verificaram que a porosidade total e a microporosidade não alteraram em dois latossolos estudados.

$\mathrm{Na}$ camada de 0,10-0,20 m pode-se verificar que não foi observada nenhuma diferença estatística entre os tratamentos para o atributo porosidade total do solo (Tabela 4). Já na camada de 0,20-0,40 m embora tenha sido observado que o tratamento com Vegetação de Cerrado obteve média estatisticamente superior ao tratamento com metade da dose de biossólido e a Consórcio Sem Insumos, o mesmo não diferiu do tratamento com Solo Exposto, dobro da dose de biossólido e com o tratamento Adubação Mineral. Outros pesquisadores afirmaram que a adição de biossólido de esgoto pode não alterar a porosidade total, independentemente da condição original do solo (FURRER, STAUFFER, 1983). 


\section{CONCLUSÕES}

Pelos resultados obtidos pode-se concluir que:

- A aplicação de biossólido de esgoto influência positivamente a densidade do solo, macroporosidade e a porosidade total na camada superficial do solo $(0-0,10 \mathrm{~m})$;

- O atributo microporosidade não se apresenta como bom indicador da qualidade física do solo.

\section{REFERÊNCIAS}

ALVES, M.C.; SUZUKI, L. G.A.S.; SUZUKI L.E.A.S. Densidade do solo e infiltração de água como indicadores da qualidade física de um Latossolo Vermelho distrófico em recuperação.

Revista Brasileira de Ciência do Solo. 2007, 31,617-625.

BELLOTE, A. F. J. ; SILVA, H. D. da. Cultivo do eucalipto: nutrição, adubação e calagem, Embrapa Floresta, ago. 2003. Disponível em:

$<\underline{\text { http://sistemasdeproducao.cnptia.embrapa.br/FontesHTML/Eucalipto/CultivodoEucalipto/> }}$. Acesso em: 03 jul. 2008.

BOEIRA, R.C.; SOUZA, M.D. Estoques de carbono orgânico e de nitrogênio, pH e densidade de um latossolo após três aplicações de lodos de esgoto. Revista Brasileira de Ciência do Solo. v. 31, p.581-590, 2007.

BRASIL. Resolução CONAMA n³75/2006 CONAMA- Conselho Nacional do Meio Ambiente., de 29/8/2006. Disponível em: <http://www.mma.gov.br/port/conama/legiano/29 Set. 2006>. Acesso em: 03 jul. 2008.

CAMPOS, F.S.; ALVES, M.C. Uso de lodo de esgoto na reestruturação de solo degradado. Revista Brasileira de Ciência do Solo, vol.32, p.1389-1397, 2008.

CETESB - COMPANHIA DE TECNOLOGIA DE SANEAMENTO AMBIENTAL. Aplicação de lodos de sistemas de tratamento biológico em áreas agrícolas - Critérios para projeto e operação. São Paulo: CETESB, 1999. 32p. (Manual Técnico, p 4.230).

EMBRAPA - EMPRESA BRASILEIRA DE PESQUISA AGROPECUÁRIA. Centro Nacional de Pesquisa de Solos. Sistema Brasileiro de Classificação de Solos. Rio de Janeiro, 2006. 306p.

EMBRAPA - EMPRESA BRASILEIRA DE PESQUISA AGROPECUÁRIA - Manual de métodos de análise de solo. 2ed. Rio de Janeiro: Embrapa/Centro Nacional de Pesquisa de Solos, 1997. $212 p$.

FREIER, M.; MALAVASI, U.C.; MALAVASI; M.M. Efeitos da aplicação de biossólido no crescimento inicial de Eucalyptus citriodora Hook. Revista de Ciências Agroveterinárias, Lages, v.5, n.2, p.102-107, 2006.

FURRER, O.J.; STAUFFER, W. Influence of sewage sludge application physical properties of soils and its contribution to the humus balance. In: THE INFLUENCE of sewage sludge applicationon physical and biological properties of soils. Dordrecht: D. Reidel. 1983, p.65-74. 
GREENLAND, D.J. Soil management and soil degradation. Journal Soil Science, vol. 31, p. 301322. 1981.

GUEDES M.C.; ANDRADE C.A.; POGGIANI F.; MATTIAZZO M.E. Propriedades químicas do solo e nutrição do eucalipto em função da aplicação de lodo de esgoto. Revista Brasileira de Ciência do Solo, v.30, p.267-280, 2006.

GUEDES, M.C.; POGGIANI, F. Variação dos teores de nutrientes foliares em eucalipto fertilizado com biossólido. Scientia Forestalis, n.63, p.188-201, 2003.

JORGE, J.A.; CAMARGO, O.A.; VALADARES, J.M.A.S. Condições físicas de um Latossolo Vermelho-Escuro quatro anos após aplicação de lodo de esgoto e calcário. Revista Brasileira de Ciência do Solo,v.15, p. 237-240. 1991.

LIMA, W.P. Impacto ambiental do eucalipto. 2.ed. São Paulo: Editora da Universidade de São Paulo, 1993. 301p.

MATTHEWS, P. Agricultural and other land uses. In: SPINOSA, 1.; VESILIND, P.A.; Sludge into Biosolids - Processing, Disposal, Utilization. IWA Publishing, 394 p, United Kingdom, 2001.

MELO, V.P.; BEUTLER, A.N.; SOUZA, Z.M.; CENTURION, J.F.; MELO, J.P. Atributos físicos de Latossolos adubados durante cinco anos com biossólido. Pesquisa Agropecuária Brasileira, vol.39, p.67-72. 2004.

NAVAS, A.; BERMÚDEZ, F.; MACHÍN, J. Influence of sewage sludge application on physical and chemical properties of Gypsisols. Geoderma. 1998,v.87, p.123-135.

NOGUEIRA, S.F. Balanço de nutrientes e avaliação de parâmetros biogeoquímicos em áreas alagadas construídas para o tratamento de esgoto. Piracicaba, 2003.

RAIJ B.V.; CANTARELLA, H.; QUAGGIO J.A.; FURLANI, A.M.C. (Eds.). Adubação orgânica. In: Recomendações de adubação e calagem para o Estado de São Paulo. 2. ed., 1997. p.30-35. (Boletim Técnico 100).

REICHERT, J.M.; REINERT, D.J.; BRAIDA, J.A. Qualidade do solo e sustentabilidade de sistemas agrícolas. Revista de Ciência Ambiental, v.27, p.29-48, 2003.

VAZ, L M. S.; GONÇALVES, J. L. de M. Crescimento inicial e fertilidadedo solo em um povoamento de Eucalyptus grandis fertilizado combiossólido. Revista Sitientibus, n. 26, p.151174. Feira de Santana, 2002. 